grams, and student bodies that are fairly reflective of broader society. While there is some clustering, the data and rankings suggest quite strongly that the links between accessibility and affordability are not straightforward. For example, with the exception of Finland and the Netherlands, no country has consistently high scores across both the affordability and accessibility rankings.

This article is adapted, with permission, from the Higher Education Digest. See also Global Higher Education Rankings: Affordability and Accessibility in Comparative Perspective 2005, Alex Usher and Amy Cervenan. Education Policy Institute, 25 Ludwell Lane, Stafford, VA 22554, USA. E-mail: info@educationalpolicy.org.

\section{Foreign Higher Education Activity in Francophone Africa LISA JOKIVIRTA}

Lisa Jokivirta is research officer at the Observatory on Borderless Higher Education. Address: Observatory on Borderless Higher Education, 36 Gordon Sq., London, WC1H OPF, UK. E-mail: I.jokivirta@obhe.ac.uk. URL: www.obhe.ac.uk.

$\mathrm{P}_{\text {has }}^{\mathrm{r}}$ revious research on foreign educational activity in Africa has mainly focused on the English-speaking parts of the continent. Based on a substantial report, this article is an attempt to gauge the scale and nature of transnational higher education in francophone Africa and to raise practical questions over the sustainability of the francophone capacity-building model versus the more revenue-generating model generally found in the anglophone world.

Francophone Africa consists of 29 countries (I8 where French is the official language, 6 where it is one of two official languages, and 5 where French is not one of the official languages but still has a powerful presence). The combined population is approximately 394 million (conflicting figures). Francophone Africa does not constitute a single political, economic, or cultural entity, and member countries exhibit a highly varied scale of foreign educational activity. There is a correlation between national economic conditions (i.e., GDP per capita) and level of foreign activity, with the least-developed countries remaining largely unaffected by this type of provision. The most active and diverse sites of transnational higher education are concentrated in the North African and Indian Ocean regions.

There is a growing demand for transnational higher education across francophone Africa. Although very few countries have developed regulatory frameworks for transnational high- er education, most governments have encouraged this type of provision in an attempt to curb study-abroad rates and maximize tertiary participation. Other perceived benefits include domestic capacity building, widening student choice, and enhancing innovation and competitiveness in the sector. Yet opportunity is matched by attendant risk. Political upheavals and uncertainty have deterred foreign investment in certain countries. There appear to be limited possibilities for institutional partnerships due to a widespread lack of local expertise. Concerns over financial risk have also been raised due to the tradition of "free university education for all." Incoming providers have reported difficulties in subsidizing the costs of tuition fees and in many cases have failed to secure local investment. The lack of regulatory framework for foreign providers might facilitate entry into the market, but concerns have also been raised over "soft market" value.

Until now, the vast majority of foreign educational projects have been spearheaded by the developed countries of the francophone world (particularly France). The Agence universitaire de la francophone (AUF), an international body dedicated to promoting a language "under threat," has been at the forefront of developments. A "top-down" capacity-building approach has been adopted, in line with the inherited francophone tradition of "free university education for all."

\section{Trends in Foreign Provision}

There would appear to be no comprehensive list of transnational higher education in francophone Africa. The Observatory on Borderless Higher Education's report provides 20 examples of both face-to-face and distance/online foreign educational activity in order to distill emerging models and trends. Large-scale foreign operations that were established prior to the mid-I990s have generally been in receipt of multilateral funding (mainly from the AUF) and are almost entirely owned and operated by a consortium of foreign actors. This could reflect an attempt to reduce operational costs and share risk management, particularly as the majority of entities continue to subsidize student fees. This scenario appears to have limited the potential for widespread access, as the majority of tuition-free programs are confronted by growing capacity problems.

There is evidence over time of greater ambition and commitment on the part of joint ventures. The overall shift is from small-scale, capacity-building projects (generally sustainable over a limited funding period) to more large-scale, economically driven ventures. There is a potential shift toward a branch campus model in countries such as Mauritius, Senegal, and Lebanon, where national authorities have explicitly invited foreign institutions to commence operations. The diversification of actors (particularly from the United States and India) suggests that not only French-speaking countries have an interest in operating in francophone Africa.

While still a minority trend, e-learning is increasingly viewed as a viable alternative to large-scale face-to-face delivery. 
Poor technological infrastructure, low bandwidth availability, and language remain important barriers to online access. There is a growing risk of overlapping activity in online and distance learning due to the proliferation of players in the market, and several e-university ventures have collapsed after the initial funding period ended.

Until now, transnational higher education in French-speaking Africa has developed in relative isolation from the other language communities on the continent. One site where the anglophone and francophone worlds meet is the African Virtual University (AVU). In March 2004, the AUF formed a partnership with the AVU to collaborate in the development of course content in French. The AVU's recent partnership with the agency might be viewed as an attempt to bridge the existing divide and promote institutional collaboration between the two language communities. The prospects of cross-fertilization (rather than ongoing separate development by language) remain unclear.

\section{ISSUES AND IMPLICATIONS}

There is currently a paucity of information on foreign educational activity in French-speaking Africa. An overview of crossborder developments suggests that transnational activity based on the capacity-building model can develop on a substantial scale, but the prospects for long-term sustainability remain less clear. Large-scale developments are almost exclusively concentrated in the more developed countries of the subregion. This trend is likely to continue as incoming providers attempt to achieve a more refined balance between developmental/commercial objectives. Mauritius, Tunisia, and Senegal offer good examples of how national governments can put in place a range of structures and incentives to bring foreign educational provision into the mainstream.

How might countries in francophone Africa maximize the developmental benefits and minimize the potential risks of transnational higher education?

It is indisputable that over the past decade transnational activity has expanded significantly in French-speaking Africa, foreign ventures have become more ambitious and the type of providers has become increasingly diverse. As cross-border activity becomes increasingly widespread across the subregion, the question begs to be raised: how might countries in francophone Africa maximize the developmental benefits and minimize the potential risks of transnational higher education? Future innovation may emphasize the value of improved data collection, tighter quality assurance, mission coordination, and impact assessment. Regional bodies such as the AUF, AVU, and the African and Malgache Higher Education Council might assume an increasingly central role in overseeing transnational developments, particularly as incoming providers move toward a more economically driven approach. Host countries might also wish to consider developing appropriate quality assurance mechanisms for imported educational activity and imposing development-based conditions on foreign establishment. Until questions are raised over the extent to which foreign provision seriously addresses the development agenda of the host country, the added-value potential of transnational higher education to the subregion will remain largely unknown.

For further details, please refer to the two-part report "Higher Education Crossing Border in Francophone Africa: Opportunities, Challenges and Implications" at www.obhe.ac.uk..

\section{Cost Sharing in Higher Education Financing: Economic Perils in Developing Countries}

\section{Carlo Salerno}

Carlo Salerno is a senior research associate at the Centre for Higher Education Policy Studies (CHEPS), University of Twente. Address: CHEPS, University of Twente, PO Box 217, 7500 AE Enschede, Netherlands. Tel: +31.53.489.2031. E-mail: c.s.salerno@bbt.utwente.nl.

Cost sharing, shifting part of the burden for financing higher education away from the state and onto students and families, is a phenomenon that has taken on global proportions. Nowhere, though, has it received greater endorsement than in the developing world and particularly in sub-Saharan Africa. A shortage of public funding, rapidly expanding enrollments, and strong endorsement from international aid agencies like the World Bank have all worked in concert to push cost sharing as the way for such nations to strengthen their fragile higher education sectors and spur economic growth.

The practice makes for sound economic policy, particularly on equity grounds. Investment in higher education yields significant private returns; and from an equity standpoint, whoever benefits ought to pay. Since both individuals and society reap the rewards from education, an equitable financing scheme implies sharing the costs. The potential gains from cost sharing are readily apparent in the success of its most ardent fans: Anglo-Saxon countries. Indeed, one of the major strengths behind the American, British, and Australian systems is their universities' ability to exploit this supplemental 